\title{
FORMAÇÃO INICIAL DE PROFESSORES DA EDUCAÇÃO DO CAMPO: A EXPERIÊNCIA DO PRONERA/UERN EM NARRATIVAS (AUTO) BIOGRÁFICAS
}

\author{
FORMACIÓN INICIAL DE PROFESORES DE EDUCACIÓN DEL CAMPO: LA \\ EXPERIENCIA DE PRONERA/UERN EN LAS NARRATIVAS (AUTO) BIOGRÁFICAS
} INITIAL FORMATION OF RURAL EDUCATION TEACHERS: THE EXPERIENCE
OF PRONERA/UERN IN BIOGRAPHICAL NARRATIVES

\author{
Ana Lúcia Oliveira AGUIAR ${ }^{1}$ \\ Emerson Augusto de MEDEIROS ${ }^{2}$
}

RESUMO: O artigo em tela apresenta reflexões construídas em um estudo dissertativo sobre a formação inicial de professores da Educação do Campo com fundamento na experiência do Programa Nacional de Educação na Reforma Agrária - PRONERA, da Universidade do estado do Rio Grande do Norte - UERN. Em parâmetros metodológicos, utilizamos da abordagem qualitativa de pesquisa e de entrevistas de histórias de vida com três formandos do Curso de Pedagogia, do Projeto de Formação Inicial Docente Pedagogia da Terra. Pensamos que na experiência da UERN, o PRONERA conseguiu efetuar um dos principais desafios relativos à formação de professores da Educação do Campo no País, qual seja: desenvolver processos formativos relacionando a formação universitária de docentes da Educação Básica com os conhecimentos, a história e a memória, as experiências de vida e as práticas culturais dos povos do campo.

PALAVRAS-CHAVE: Formação inicial de professores. Educação do campo. PRONERA.

RESUMEN: El artículo en pantalla presenta reflexiones construidas en un estudio argumentativo sobre la formación inicial de docentes de educación del campo basado en la experiencia del programa nacional de educación en reforma agraria - PRONERA, de la Universidad del estado de río Big North-UERN. En parámetros metodológicos, utilizamos el enfoque cualitativo de investigación y entrevistas de historias de vida con tres egresados del curso de pedagogía, del proyecto de formación inicial docente de pedagogía de la tierra. Creemos que en la experiencia de UERN, PRONERA ha logrado hacer uno de los principales retos en la formación de docentes de la educación sobre el terreno en el país, que es: desarrollar procesos formativos relacionados con la formación universitaria de profesores de la Educación básica con el conocimiento, la historia y la memoria, experiencias de vida y prácticas culturales de los pueblos del campo.

${ }^{1}$ Universidade do Estado do Rio Grande do Norte (UERN), Mossoró - RN - Brasil. Professora Adjunta do Departamento de Educação e Docente do Programa de Pós-Graduação em Educação (POSEDUC/UERN). Doutora em Sociologia. Realizou Estágio Pós-Doutoral em Educação pela Universidade Federal do Ceará (UFC). ORCID: <http://orcid.org/0000-0003-3626-2427>. E-mail: aguiarpietro@gmail.com.

${ }^{2}$ Universidade Federal Rural do Semi-Árido (UFERSA), Mossoró - RN - Brasil. Professor Assistente do Departamento de Ciências Humanas. Doutorando em Educação pelo Programa de Pós-Graduação em Educação da Universidade Estadual do Ceará (UECE). Bolsista do Programa PRODOUTORAL/CAPES. ORCID: <http://orcid.org/0000-0003-3988-3915>. E-mail: emerson.medeiros@ ufersa.edu.br.

RPGE- Revista on line de Política e Gestão Educacional, Araraquara, v. 22, n. 3, p. 1124-1139, set./dez., 2018. E-ISSN:1519-9029. DOI: $10.22633 /$ rpge.v22i3.11789 
PALABRAS CLAVE: Formacíon inicial de mestros. Educação del campo. PRONERA.

ABSTRACT: The article on screen presents reflections built in a argumentative study on the initial formation of education teachers of the field based on the experience of the National Program of Education in agrarian reform - PRONERA, of the University of the state of Rio Big North-UERN. In methodological parameters, we made use of the qualitative approach of research and interviews of life stories with three graduates of the pedagogy course, the initial education project of Terra-UERN. We believe that in the experience of UERN, PRONERA has achieved one of the main challenges in the formation of teachers of the field education in the country, which is: to develop formative processes that relate the university training of faculty members of the Basic education with the knowledge, history and memory, life experiences and cultural practices of the peoples of the countryside.

KEYWORDS: Initial teacher formation. Rural education. PRONERA.

\section{Introdução}

O texto tenciona construir uma discussão sobre a formação inicial de professores da Educação do Campo com base na experiência do Programa Nacional de Educação na Reforma Agrária - PRONERA, da Universidade do estado do Rio Grande do Norte - UERN, por meio do Projeto de Formação Inicial Docente intitulado de Pedagogia da Terra. Salientamos que a investigação advém de um trabalho dissertativo desenvolvido no Mestrado em Educação do Programa de Pós-Graduação em Educação - POSEDUC, da Universidade do estado do Rio Grande do Norte - UERN. A investigação ancorou-se em narrativas (auto) biográficas dos sujeitos da pesquisa.

Os estudos com (auto) biografias, segundo Delory-Momberger (2008), vêm crescendo fortemente no cenário educativo contemporâneo. Enquanto conjunto de representações que o sujeito constrói da própria vida e de sua trajetória, a história de vida tornou-se um componente e um dispositivo metodológico no campo da pesquisa em Educação (NÓVOA, 1995; PINEAU, 2006; SOUZA, 2006; MEDEIROS; AGUIAR, 2018).

Nesse contexto, subsidiando-se nas histórias de vida de três formandos do Curso de Licenciatura em Pedagogia, do Projeto de Formação Inicial Docente Pedagogia da Terra/UERN, objetivamos pensar sobre a experiência do PRONERA desenvolvida na Universidade do estado do Rio Grande do Norte - UERN. Considerando a amplitude da discussão, apresentaremos aqui parte das trajetórias educativas vividas pelos sujeitos 
participantes do estudo. Referenciamos ainda que duas professoras-formadoras ${ }^{3}$, as quais lecionaram e participaram da formação no Curso de Licenciatura em Pedagogia, do Projeto Pedagogia da Terra - UERN, também dialogaram na investigação. Seus relatos foram importantes para entendermos contextos do período formativo e de práticas educativas exercidas com os alunos.

A pesquisa fundamentou-se na abordagem qualitativa de investigação, a qual entende as práticas sociais como atividades humanas carregadas de significados e de sentidos que podem se tornar, a partir da análise e da compreensão científica, em referências para refletirmos a respeito do mundo social em que habitamos (MINAYO, 2007; MEDEIROS; VARELA; NUNES, 2017). Como técnica de coleta de informações para o estudo, utilizamos das entrevistas de histórias de vida, as quais centraram sua atenção para recortes de experiências de formação no processo formativo (ALBERTI, 2005).

Traçada esta breve introdução, informamos que o restante do texto encontra-se organizado em três seções. Inicialmente, abordaremos, de modo sucinto, o PRONERA na Universidade do estado do Rio Grande do Norte - UERN. Em segundo instante, discutiremos a formação inicial de professores da Educação do Campo e o contexto formativo vivido no Curso de Pedagogia, do Projeto Pedagogia da Terra - UERN, articulando-o com as narrativas (auto) biográficas dos formandos, sujeitos do estudo, e com as professoras-formadoras que colaboraram na investigação. Declaramos que além de terem vivido a formação docente no Curso de Pedagogia, do Projeto Pedagogia da Terra - UERN, os formandos são docentes em espaços de educação formal e não formal em áreas rurais no estado do Rio Grande do Norte. Por último, teceremos as considerações oriundas da investigação.

\section{O PRONERA/UERN: configurações da Licenciatura em Pedagogia, do Projeto Pedagogia da Terra}

Antes de adentrarmos na proposta de formação que embasou o Programa Nacional de Educação na Reforma Agrária - PRONERA, da Universidade do estado do Rio Grande do Norte - UERN, esclarecemos que seu surgimento, a nível nacional, data do ano de 1998. Essa política pública destinada à Educação das populações rurais se preocupou, entre outros pontos, com a formação de professores da Educação do Campo no Brasil (SANTOS; SILVA, 2016; MEDEIROS; FERREIRA; AGUIAR, 2018).

\footnotetext{
3 Para resguardar as identidades dos três participantes da pesquisa, utilizaremos dos termos Formanda " $\mathrm{A}$ ", Formanda "B" e Formando "C" para se referir aos mesmos. No que toca às professoras-formadoras nos reportaremos às expressões Professora-Formadora "A" e Professora-Formadora "B". 
No âmbito do Projeto de Formação Inicial Docente concebido como Pedagogia da Terra, sua inserção se fez com a criação de cursos de Licenciatura em Pedagogia em universidades públicas das esferas municipal, estadual e federal de ensino, com o objetivo maior de formar professores para atuação na Educação Infantil, nos anos iniciais do Ensino Fundamental e na modalidade de Educação de Jovens e Adultos da Educação Básica no Campo. O primeiro curso teve início na Universidade Regional do Noroeste do Rio Grande do Sul - UNIJUÍ, o qual se consolidou a partir da parceria entre a instituição ofertante, o Movimento dos Trabalhadores Rurais Sem Terra - MST e o Instituto Técnico de Capacitação e Pesquisa da Reforma Agrária - ITERRA, com apoio financeiro do Instituto de Colonização e Reforma Agrária - INCRA (MEDEIROS; FERREIRA; AGUIAR, 2018).

Depois da experiência inicial, outras universidades públicas do País aderiram à inclusão do projeto de formação docente com a criação de novas turmas. Na Região Nordeste, segundo Medeiros, Ferreira e Aguiar (2018), a primeira experiência se efetuou na Universidade Federal do Rio Grande do Norte - UFRN, no ano de 2002.

Em relação à Universidade do estado do Rio Grande do Norte - UERN, o PRONERA, por meio do Projeto Pedagogia da Terra, adentrou com o desenvolvimento de cinco turmas, as quais se firmaram como fruto de um convênio entre a instituição e o INCRA, com o apoio do MST e da Federação dos Trabalhadores na Agricultura do Rio Grande do Norte - FETARN. Seguindo, em parte, a pauta nacional dessas licenciaturas, reforçou como objetivo central,

Licenciar pedagogos, em Nível Superior, para atuação docente no Primeiro Segmento do Ensino Fundamental, no sistema regular e na modalidade Educação de Jovens e Adultos; e para o exercício profissional de atividades de Coordenação e de Assessoramento Pedagógico em escolas, instituições dos sistemas educacionais, e projetos educativos, escolares ou não escolares, preferencialmente os das áreas de assentamento da Reforma Agrária (UNIVERSIDADE DO ESTADO DO RIO GRANDE DO NORTE, 2006, p. 25).

Para ingresso no Curso, foi ofertada a quantidade de 180 vagas, as quais se distribuíram nas cinco turmas formadas (60 vagas por turma). $\mathrm{O}$ início das atividades formativas data do ano de 2006, e a conclusão do projeto de formação docente marca o ano de 2011. Do número de ingressantes, concluíram a graduação 156 formandos pertencentes a 10 municípios do estado do Rio Grande do Norte, a saber: Apodi (14), Areia Branca (04), Assú (02), Baraúna (18), Caraúbas (01), Carnaubais (01), Governador Dix-Sept Rosado (15), Mossoró (61), Felipe Guerra (01) e Upanema - RN (39).

Como dimensão metodológica do Curso foi materializada a Pedagogia da Alternância, com etapas de estudos presenciais na Universidade (ou espaços equivalentes), período 
nominado de Tempo Escola/Universidade, e etapas de estudos nas comunidades de vivência dos formandos, instante conferido como Tempo Comunidade. A referida licenciatura teve uma carga horária de 2.805 horas distribuídas em seis módulos ou semestres letivos. $\mathrm{Na}$ instituição, sua proposta oficial curricular se fundamentou, na época, nas Diretrizes Curriculares Nacionais para a Formação de Professores da Educação Básica (Resolução CNE/CP n ${ }^{\circ}$ 1, de 18 de fevereiro de 2002), e na Resolução 06/99 do Conselho de Ensino, Pesquisa e Extensão - CONSEPE/UERN (UNIVERSIDADE DO ESTADO DO RIO GRANDE DO NORTE, 2006).

O Projeto Pedagógico de Curso (2006) enfatizou que os fundamentos epistemológicos, ontológicos e metodológicos da formação docente se ancoraram na Pedagogia de Paulo Freire, priorizando o diálogo entre os conhecimentos científicos e os conhecimentos produzidos no cotidiano dos sujeitos em processo formativo. Os ementários do conjunto de disciplinas da matriz curricular além de salientarem os saberes e os conhecimentos necessários à formação do professor, de acordo com a legislação educacional vigente, deveriam se articular à realidade de vida e educacional das populações rurais. Para tanto, o estudo da Educação do Campo se apresentou com hegemonia no projeto oficial de formação desenvolvido.

Ditas essas palavras, o PRONERA/UERN, com o desenvolvimento do Curso de Pedagogia, do Projeto Pedagogia da Terra, perspectivou somar na qualificação profissional de professores para atuação docente em espaços educativos no meio rural, o que a longo prazo poderá contribuir para a melhoria da qualidade da Educação do Campo no estado do Rio Grande do Norte.

\section{Formação Inicial de Professores da Educação do Campo: vivências na Licenciatura em Pedagogia, do Projeto Pedagogia da Terra - PRONERA/UERN}

No arcabouço teórico que fundamenta a formação de professores da Educação do Campo está presente uma concepção de formação que valida o saber originado das experiências cotidianas dos povos do campo, das suas culturas, das suas formas de produção, o respeito e o compromisso com a história e a memória, preservando-as e (re) significando-as em suas realidades locais (MOLINA, 2006; ARROYO; CALDART; MOLINA, 2008; CALDART, 2012).

Como reflete Caldart (2012), a formação de professores da Educação do Campo deve se alimentar, no seu sentido amplo, da diversidade cultural transitante nos espaços de vivência 
de seus sujeitos. Imbuída na busca da compreensão do mundo, do contexto histórico e plural do campo, essa formação não pode se legitimar em aprendizagens abstratas que relega a interdependência com a terra e com o lugar de vida do camponês, o qual consagrou sua existência e a de seu povo.

É patente na literatura nacional e internacional a relevância da contextualização na formação do professor com sua realidade social, histórica, política e cultural. O Curso de Pedagogia, do Projeto Pedagogia da Terra - UERN viu como importante na formação,

O fortalecimento da identidade dos homens e das mulheres do meio rural; a valorização dos seus conhecimentos servindo de âncora para a apropriação de outros saberes culturais, produzidos em outros contextos. Um dos desafios do Projeto Pedagogia da Terra da UERN foi reconhecer, favorecer e ampliar, a constituição de uma Licenciatura em Pedagogia que garantisse, dentro dos espaços educativos do campo, a autenticidade da cultura lá produzida (UNIVERSIDADE DO ESTADO DO RIO GRANDE DO NORTE, 2011, p. 12).

Formação construída a partir de um contexto específico que aos poucos foi articulando conhecimento e vida, história e saber, experiência e Ciência. As narrativas dos formandos certificam:

Eu pouco fazia ideia do que era ser universitário né, o que era ser professor. [...] No primeiro dia de aula eu pensava que tudo ia ser muito diferente do que eu vivia aqui no Assentamento Esperança. Claro que foi diferente porque a gente estava em lugares diferentes. Porque a entrada na universidade é outro mundo. [...] Passei por muitas mudanças. [...] Eu mudei na forma de olhar a realidade, de ensinar né. [...] As leituras, os momentos com colegas de lugares bem diferentes né, os estudos que fazíamos no Assentamento me ajudaram demais a entender né, a educação no meio rural. [...] a formação me deu um olhar para ver a educação daqui e como ela deve ser feita. [...] Desde o primeiro período entrei em contato com o Campo. [...] fiz pesquisas de campo que foram importantes para conhecer a realidade do Assentamento. [...] os alunos ficavam surpresos porque ao irem a campo conheciam aquilo que fazia parte de sua vida e passava por despercebido, nós entramos em contato com nossa história e isso era bom porque nós tomávamos consciência da realidade, nós também estudamos nossa história. [...] Na disciplina dos Movimentos Sociais ${ }^{4}$ fiz uma pesquisa de campo para conhecer a história do Assentamento Esperança, fiz um portfólio nessa disciplina e assim, nele tive que contar também minha história. [...] Assim, eu fiquei surpreso porque nem eu sabia como é a realidade, aquela realidade, [...] das pessoas que participaram do assentamento, do seu início. [...] as aulas presenciais, as atividades da maioria dos professores tinha muita coisa ligada ao nosso mundo daqui, até porque o Curso tinha essa finalidade né. [...] Eu fui conhecendo realmente um campo que assim né, eu já vivia, mas

${ }^{4} \mathrm{O}$ Formando "C" refere-se à disciplina "Sociologia dos Movimentos Sociais e Educacionais". 
não tinha consciência disso (Entrevista realizada com o Formando "C"5, Assentamento Esperança, Upanema/RN).

Meu primeiro dia de aula foi em um teatro, foi a aula inaugural, eu nem acreditava que estava entrando na universidade. Sonhei demais com a faculdade. [...] eu já era professora, e assim, eu sabia da importância que o Curso poderia trazer para mim e também para os meus alunos. [...] Eu era tímida no início, [...] tinha aquele receio, você está em um ambiente novo, então isso causa timidez, mas assim eu era participativa, porque eu já era professora, então a experiência em sala de aula com meus alunos me tirou a vergonha. [...] As aulas no Pedagogia da Terra [...] eram muito produtivas, os professores se esforçavam para dar o melhor de si. [...] Eu via que muitos não conheciam a realidade do campo, mas o bom disso foi porque eles também aprenderam com a gente. [...] houve aprendizagens marcantes, teve uma aula em que nós tínhamos que trazer do campo aquilo que era bem característico de nossa região. [...] os alunos levaram muita coisa. [...] uns apresentaram a culinária, outros já apresentaram as lendas, as roupas, os artesanatos, cada um tinha algo diferente. Nesse dia, eu acho que a aula era da disciplina Processos de Alfabetização, foi um dos dias mais ricos que eu tive no Curso, a gente nessa aula viu o quanto o campo é rico. [...] o professor dessa disciplina foi um dos melhores, tivemos muitos professores bons, [...] nas aulas tinham debates dos textos, e assim, como era relacionado ao campo, então para quem vivia nele era mais fácil de compreender. [...] o Pedagogia da Terra ele tinha na sua proposta né, preparar a gente para ser professor em qualquer lugar, mas para quem vive no Campo foi bem melhor. [...] Os alunos na sua maioria, sabiam muita coisa. Então ficava mais fácil aprender. [...] Como eu disse, teve momentos ricos. Vemos muito no Curso Paulo Freire, acho que Freinet, os movimentos sociais. A gente estudou o Campo, assim, a educação que deve ser feita para o Campo. Eu aprendi a ensinar melhor, e algo que eu destaco era eu já ser professora, aos poucos eu fui melhorando minha forma de ensinar, [...] mesmo sem saber, eu não era tradicional, sempre deixei meu aluno explorar né para aprender, [...] e a formação no Curso aprimorou isso, agora parecia que tinha mais autonomia, eu sabia o porquê daquilo que fazia, assim, a importância de valorizar a idade, de buscar entender a família e trazer ela mais para a escola, de trabalhar o Campo mesmo, as coisas daqui em minha prática, isso aprendi no Pedagogia da Terra, então assim ter a formação e ao mesmo tempo ensinar me fez aprender demais, principalmente porque eu era professora no Campo (Entrevista realizada com a Formanda "A", Assentamento Nova Vida, Upanema/RN).

Freire (2010), em seus escritos, sustenta a ideia de que todo processo de formação do sujeito está inserido em uma cultura e em uma história, não há como pensá-lo fora de seu contexto. A formação se faz na vivência do real, integrando a isso o sujeito, suas histórias, seus conhecimentos, suas experiências e suas práticas culturais, isto é, as dimensões que fazem e formam a sua totalidade.

Acrescenta Tardif (2010), que a formação do professor não deve se compor apenas do conhecimento científico e da academia, ela deve perpassar uma rede de conexões,

${ }^{5}$ Os participantes do estudo assinaram um Termo de Consentimento Livre e Esclarecido permitindo a divulgação de suas histórias e de suas narrativas (auto) biográficas para o trabalho investigativo.

RPGE- Revista on line de Política e Gestão Educacional, Araraquara, v. 22, n. 3, p. 1124-1139, set./dez., 2018. E-ISSN:1519-9029. DOI: $10.22633 /$ rpge.v22i3.11789 
transcendendo aos muros do conhecimento técnico e disciplinar. Ela também deve resultar de uma negociação entre diversos grupos (a sociedade, a universidade, os sistemas de ensino, entre outros), sustentando-se nos conhecimentos desenvolvidos nas experiências de vida, que são frutos de uma gama de vivências do sujeito com e no mundo.

Entendemos que a formação do professor se produz em um processo de compreensão dos fenômenos educativos, mas, para além disso, na compreensão dos processos sociais, históricos e pessoais do sujeito em formação. Sendo assim, a formação inicial deve contribuir para criar nos formandos hábitos de reflexão e de autorreflexão que são essenciais numa profissão, a qual não se esgota em matrizes científicas ou mesmo pedagógicas.

Nóvoa (1995), ao discutir a formação no livro "Vida de Professores", inscreve que o professor é uma pessoa com historicidade, produzindo sua identidade no seu processo de aprendizagem. Colocar sua realidade nas dimensões que fomentam a formação é fundamental, na medida em que permite entender o significado do desenvolvimento social presente em seu meio.

O Formando "C", participante do estudo, ao contar sua itinerância na academia, no Curso de Pedagogia, do Projeto Pedagogia da Terra - UERN, articula que a formação vivida esteve entrelaçada à sua vida. Para ele, desde o primeiro período houve estudos acerca do Campo. O contato com a realidade (a história do Assentamento Esperança, como também sua própria história), as leituras, os momentos com colegas e amigos de diferentes localidades no Curso e as pesquisas de campo, despertaram nele e em outros viventes desse processo a consciência do conhecimento histórico de seu povo, de seu meio, a consciência de sua condição de ser camponês e assentado.

Recordando Freire (2005, p. 31), citamos que "todo aprendizado deve encontrar-se intimamente associado à tomada de consciência da situação real vivida pelo educando". Construindo consciência de sua existência e da situação real de sua comunidade, o sujeito pode intervir no mundo e assim transformá-lo.

O Formando "C" identifica que a formação na licenciatura deu-lhe condições de desenvolver um olhar a respeito da Educação que deve coexistir no campo, clarificando sua percepção a respeito do que é ser professor: “a formação me deu um olhar para ver a educação daqui e como ela deve ser feita".

Como bem mostra seu depoimento, observamos que a proposta de formação do Curso preocupou-se com a realidade social expressa no Campo. O Curso de Pedagogia, do Projeto Pedagogia da Terra - UERN, ao intentar desenvolver um trabalho de formação, no qual o 
campo e a universidade celebram o conhecimento, contempla aos participantes da formação relacionar a cultura, a profissão professor e a Educação.

A Formanda "A", ao descrever sua formação na Licenciatura em Pedagogia, do Projeto Pedagogia da Terra - UERN, principia sua narrativa referenciando os momentos iniciais de vivência na academia. A realização do sonho de ser universitária aparece claramente em sua fala. Ela acrescenta a timidez frente ao novo mundo que se apresentou, sendo uma característica em sua personalidade, reforçando a ajuda que teve de sua experiência profissional (já ser professora) para superá-la.

Como momentos de troca e de construções de conhecimento no processo formativo, a Formanda "A" mostra a relação com os professores-formadores. Em sua narrativa, ela diz que alguns dos professores-formadores não conheciam a realidade no meio rural, porém nas aulas, ao atentarem ao diálogo do Campo (realidade dos graduandos) com os saberes científicos e disciplinares intrínsecos à prática do professor-formador, a aprendizagem e a formação se faziam.

$\mathrm{Na}$ interioridade de sua narrativa (auto) biográfica, a Formanda "A" explana aulas em que o Campo veio à universidade: "teve uma aula em que nós tínhamos que trazer do Campo aquilo que era bem característico de nossa região". Suplementa também que o diálogo entre Campo e Universidade colaborou na apreensão de novos saberes, ajudando a desenvolver seu fazer docente na Educação do Campo.

Freire (2005, p. 134) afirma que "o diálogo como encontro dos homens para a 'pronúncia' do mundo, é uma condição fundamental para sua real humanização". Nesse caminho, a formação de professores da Educação do Campo não pode ser considerada como algo doado pela universidade. É uma construção de conhecimentos que se alimenta nos saberes dos povos do campo e nos saberes científicos, portanto, uma ação comprometida que conduz à participação efetiva de todos de forma horizontal.

Concebemos que alguns dos objetivos específicos contidos no Projeto Pedagógico de Curso (2006) encontram-se com os escritos anteriores. Vejamos o que proposita o documento curricular oficial:

O Curso Pedagogia da Terra tem como objetivos específicos:

Valorizar os saberes e a carga de conhecimentos dos homens e mulheres do Campo;

Colaborar efetivamente na construção de uma proposta pedagógica que contribua com novos conhecimentos para garantir a qualidade de vida do homem e da mulher do campo;

Contribuir à construção da capacidade do homem e da mulher do campo de pensar e agir com autonomia a partir de suas próprias forças, recursos e 
potencialidades, individualmente e enquanto classe social (UNIVERSIDADE DO ESTADO DO RIO GRANDE DO NORTE, 2006, p. $27)^{6}$.

A dinâmica da formação de professores da Educação do Campo pode ser pensada pela sua vinculação com a realidade educacional no Campo, tendo por referência a apropriação dos saberes dos formandos, saberes construídos, muitas vezes, a partir da interação homem e natureza, em seus cotidianos de vida (MOLINA, 2006; CALDART, 2012).

Pineau (2010) defende que o sujeito antes de chegar à formação perpassa por três movimentos essenciais no processo de construção. Não há formação sem nos situarmos no contexto social, no outro e nas relações com o outro (heteroformação), no mundo físico e natural (ecoformação), e em si próprio (autoformação). Esse autor entende que a formação é resultado das permanentes transformações entre o outro, o mundo e o sujeito.

$\mathrm{Na}$ Licenciatura em Pedagogia, do Projeto Pedagogia da Terra - UERN, os alunos vivenciaram o Campo, seus espaços físicos, suas realidades, nos termos de Josso (2010), caminharam para si no sentido de revisitarem origens históricas do meio rural. A narrativa (auto) biográfica da Formanda "B" complementa:

Não tenho dúvida [...] sobre o Curso ter se voltado mesmo para o Campo. A Pedagogia da Alternância, que deixava a gente estudar um tempo na Faculdade e outro aqui no Campo é uma das provas. [...] você estudava as teorias, os conteúdos e depois você ia para o Campo, [...] então você pode aprender com a prática, entrando em contato com a realidade. [...] sem contar que muito do que se ensinava tinha ligação com o rural. Os seminários, as oficinas, [...] o espírito da formação no Pedagogia da Terra voltava-se para cá. Nas turmas do MST, tinha a mística né que é um ritual do camponês, do assentado. [...] O Curso conseguiu de tal forma ser para o professor do campo que criamos até uma banda por nome de 'Som da Terra'. A banda era de alunos do Pedagogia da Terra, os alunos cantavam, faziam músicas que tivessem afinidades com o campo mesmo. [...] Eu vejo como característica também do Curso a questão ambiental, a educação ambiental. Isso repercutiu na gente, faz você olhar o ambiente, a terra, como cuidamos dela e também nos olhar como camponeses e o que estamos fazendo. [...] A formação no Curso de Pedagogia da Terra foi uma formação que ia mesmo ao encontro com o Campo, eu posso assim afirmar que eu conheci um Campo. Os conhecimentos que eu tinha sobre aqui só se ampliaram, é como se eles tivessem adquirido consistência. [...] Hoje eu trabalho com os alunos dessa forma. Tem que partir daqui para chegar no distante. [...] As aulas sem dúvida mesmo fizeram com que a história do Campo né, os saberes da terra fossem válidos. [...] E o que foi interessante é porque os professores também aprendiam. [...] Em uma aula no Estágio, minha professora ficou impressionada em um momento que os alunos do Estágio contaram suas vidas. Assim, eles não imaginavam que o Campo tinha um mundo de coisa para se descobrir. [...] Eu mudei por demais, porque esse contato na

${ }^{6}$ O Curso de Pedagogia, do Projeto Pedagogia da Terra - UERN, ainda apresenta mais três objetivos específicos para a formação de professores. Para conhecê-los, orientamos a leitura do Projeto Pedagógico de Curso (2006). 
formação com o Campo fez eu entrar em contato comigo também. [...] Foi uma formação assim que me fez ver de tudo, o Campo né, quem vive nele e a mim também (Entrevista realizada com a Formanda "B", Comunidade Várzea Redonda, Upanema/RN).

Nos dizeres da Formanda "B" se presencia uma formação voltada para a totalidade: 0 mundo, o outro e a si mesmo. A formação não é exclusiva da/na sala de aula. A Pedagogia da Alternância, citada por ela, muito além do que as idas e vindas da comunidade para a universidade e da universidade para a comunidade, se caracteriza por proporcionar a busca pela socialização do saber, a valorização da cultura do Campo, bem como um diálogo para o aprofundamento científico e aprimoramento desses saberes em vista da compreensão e transformação do meio (GIMONET, 2007).

Os seminários e as oficinas, ambos reportados ao Campo, e a educação ambiental, mencionados pela Formanda "B", são eixos dessa formação. São referências do entrecruzamento do Campo com a Universidade. Isto posto, é inegável que a formação no Curso de Pedagogia, do Projeto Pedagogia da Terra - UERN, preocupou-se em formar professores para as várias dimensões da vida. Não somente o intelecto e as habilidades manuais, mas a formação política, inserida em valores e na cultura do Campo entrou em sintonia com a vida.

Nas entrevistas construídas com as duas professoras-formadoras do Curso de Pedagogia, do Projeto Pedagogia da Terra - UERN, as narrativas (auto) biográficas anteriores ganham mais significação e consistência:

A palavra Pedagogia da Terra é uma palavra que está dentro de mim, é minha raiz, meu berço, a terra. E a Pedagogia da Terra é porque como camponesa que sou [...] a natureza sempre foi minha educadora, eu tive a céu aberto a Pedagogia que eu precisava para essa relação com a natureza e a força que declarava e denunciava da minha identidade. Essas dimensões terra e natureza me fortalecem até hoje. Quando eu vi o título para o Pedagogia da Terra eu não sabia como ia ser aqui em Mossoró, na UERN, me inscrevi, foi uma concorrência muito grande [...] e fui aprovada, logo para o primeiro grupo de professores. [...] Então assim, uns iriam para as turmas do MST e uns iriam para as turmas da FETARN. As aulas da FETARN iam ser aqui no Campus Central, e as das turmas do MST na Fazenda São João ${ }^{7}$. Eu fui para as turmas do MST [...]. Então nos dias de aula, o carro levava os professores para a Fazenda São João, [...] lá iniciava todo o trabalho com a mística, todos os alunos que vinham de assentamentos distantes para as aulas na Fazenda São João viviam a mística, a mística do plantio, a mística da relação com a terra, os produtos estavam ali no chão, os instrumentos de trabalho estavam ali no chão, e os meninos faziam aquela mística que era exatamente o ritual de contato com a terra, de entrega a terra e o ritual de plantio e finalizando o ritual com a apresentação de toda

${ }^{7}$ A fazenda São João fica situada no Assentamento Esperança, Mossoró/RN. 
produção advinda dessa luta, do labor com a terra. [...] As aulas eram no galpão, a céu aberto, ao lado de toda essa área estávamos frequentemente sendo visitados pelo gado, por caprinos e suínos. Então nós ouvíamos os sons da natureza ligados aos sons dos conteúdos, então os conteúdos quando eu falava do homem e sua cultura, o homem histórico, geográfico e cultural. [...] Nós estávamos ali alimentados e regados pela cultura presente não só pelos sujeitos da cultura do Campo, mas pelos elementos da cultura desse Campo. [...] os alunos produziram bastante do ponto de vista das histórias de vida e também dos saberes da terra, do Campo, nós fizemos um plano de aula para as sessenta horas para o contexto local. [...] A história de vida dos alunos foram trabalhadas em suas várias dimensões, essa história junto a terra, a família, aos saberes que eles possuem, a cultura, as práticas que exerciam nos seus lugares. [...] isso foi feito para que eles entendessem como a terra, a grande pedagoga, ensina a eles serem camponeses. [...] Era uma rede de conversas que não parava, os vínculos eram tecidos presencialmente, cada um se via na história do outro (Entrevista realizada com a ProfessoraFormadora "A", Mossoró/RN).

Eu participei da elaboração do projeto, sendo professora da Faculdade de Educação da UERN, também ministrei uma oficina com os alunos do Curso Pedagogia da Terra. [...] Na elaboração do projeto o que foi mais situado foi a questão da formação desse acadêmico, considerando a sua historicidade, sua realidade do Campo. [...] Os movimentos que participaram, principalmente o MST deixou claro que não queria uma formação qualquer para o professor, ele queria uma formação que envolvesse o campo, sua contextualização. Os movimentos queriam uma formação do professor para o campo! A partir disso, o que se foi planejado no Curso teve que considerar esse ponto. [...] Sobre a oficina que ministrei, a primeira oficina das que aconteceram, foi conhecer esse acadêmico camponês, a carga de conhecimento, de saberes que ele possuía, fazendo é claro o reconhecimento por parte dele de sua história, porque ele futuramente voltará ao campo, para contribuir na educação de sua comunidade. [...] essa oficina foi realizada com as cinco turmas, ficando eu responsável pelas turmas da FETARN e uma outra professora pelas duas turmas do MST. [...] a Metodologia utilizada né foi a (auto) biografia. Eu iniciei a aula com uma brincadeira bem conhecida pelos professores que é "a caixa de pandora". Nessa brincadeira nós instigamos a esse aluno pensar em algo ou em alguém que poderá ajudálo a realizar seus sonhos e esse alguém ou algo está na caixa, essa chamada de pandora. [...] depois que ele pensa nesse alguém ou em algo, ele irá à caixa encontrar e o que vê é a si, sua imagem. Então foi a partir dessa brincadeira que eles começaram a si ver como camponeses, pessoas capazes de realizar seus sonhos. [...] Depois desse momento, cada um contou seu sonho, sua história em um texto escrito e socializamos, montamos um mural histórico do Campo. [...] Ali, no mural, estava a história de cada um, a história ou as histórias do campo. [...] No momento da socialização, eles identificavam as semelhanças em suas vidas, os conhecimentos que tinham, formando-se, tendo seu conhecimento como suporte (Entrevista realizada com a Professora-Formadora "B", Mossoró/RN).

As falas das duas professoras-formadoras aproximam-se de toda a discussão tecida ao longo deste texto. Os conhecimentos, as histórias de vida, as experiências e as práticas culturais dos formandos, a cultura camponesa, a terra e o camponês tiveram no Curso de 
Pedagogia, do Projeto Pedagogia da terra - UERN, a oportunidade de articularem-se com a academia e com o processo de formação.

As aulas descritas pelos formandos e pelas professoras-formadoras denotam uma riqueza de conhecimentos construída. Os percursos formativos foram desenvolvidos a partir da vida social, do Campo, do que foi feito em suas histórias de vida, do regado em sua itinerância. Ao passo em que os encontros se firmavam, aflorava a reflexão, uma educação para o campo, uma educação do e no campo. A formação acontecia junto aos trajetos históricos, sendo isso um dos motes norteadores desse processo.

Cada professora-formadora expressou na narrativa uma Pedagogia da Terra, nas disciplinas e oficinas e em suas práticas educativas; cada professora atentou à sensibilidade de olhar para o Campo, à conscientização e à humanização de todos imbricados na formação.

Finalizamos este momento realçando a importância do referido projeto de formação docente para a Educação do Campo no estado do Rio Grande do Norte. A atuação docente em espaços no meio rural necessita de professores comprometidos e críticos com a realidade dos inúmeros campos brasileiros, espaços territoriais marcados pelas desigualdades sociais de classe e pela exclusão de suas populações em relação ao direito à Educação. Formar professores que reconheçam a luta histórica dos povos do campo no Brasil requer fazê-la (a formação) com base no que produzem os sujeitos do campo em sua historicidade. Desse modo, pensamos que a Licenciatura em Pedagogia, do Projeto Pedagogia da Terra - UERN, se desenvolveu na perspectiva de alcançar esse difícil objetivo.

\section{Considerações finais}

Nas últimas duas décadas - a partir de 1997 - temos visto no País um movimento educacional lutar pelo direito equitativo à Educação para as populações que vivem no meio rural. Tal movimento, nominado de Educação do Campo, por meio de suas incontáveis lutas, tem alcançado algumas vitórias, a exemplo do PRONERA, mesmo que ainda insuficientes para transformar o quadro existente quanto à realidade educacional. Neste texto, registramos, em breves linhas, a experiência do PRONERA/UERN com o desenvolvimento do Curso de Pedagogia do Projeto Pedagogia da Terra.

Como conclusão das reflexões levantadas, pensamos que na experiência da UERN, o PRONERA conseguiu efetuar um dos principais desafios relativos à formação de professores da Educação do Campo, qual seja: desenvolver processos formativos que relacionem a 
formação universitária com os conhecimentos, a história e a memória, as experiências de vida e as práticas culturais dos povos do campo.

É público em estudos (MOLINA; ANTUNES-ROCHA, 2014; HAGE, 2014) que a Educação para as populações rurais sempre esteve sob o ímpeto da inferioridade. O termo adaptação é uma prova concreta dessa afirmativa. Na legislação educacional, esse vocábulo se perpetua. Na maioria das vezes, nos documentos oficiais legislativos há um parágrafo ou um artigo complementar que se reporta à Educação para os povos rurais. Adaptar o currículo e o calendário escolar, adaptar as práticas educativas, adaptar o livro didático, entre outros, são aspectos que se vivificam quando nos dirigimos à Educação no campo.

Diferente do que afirmamos, a experiência no PRONERA/UERN, nas narrativas (auto) biográficas, elucidou momentos no processo formativo no Curso de Pedagogia do Projeto Pedagogia da Terra, que nos motivam a pensar em caminhos possíveis de formar professores com especificidades para atuação em espaços formais e não formais no campo.

De maneira geral, sabemos que a ação construída, por meio do PRONERA, ainda é pequena, diante da grande fragilidade que há quanto à ausência de professores formados, em nível superior, para a Educação do Campo, porém, é uma ação válida, posto que confirma a importância de políticas públicas implementadas com os verdadeiros sujeitos interessados em sua produção - os sujeitos do campo. O PRONERA/UERN enfatizou em sua prática o protagonismo de professores-formadores e de formandos, representantes dos movimentos sociais que compõem o projeto de formação inicial docente, na consolidação do processo formativo.

\section{REFERÊNCIAS}

ALBERTI, Verena. Manual de História Oral. 3. ed. Rio de Janeiro: Editora FGV, 2005.

ARROYO, Miguel; CALDART, Roseli Salete; MOLINA, Mônica Castagna (Orgs.). Por uma educação no campo, Petrópolis, RJ: Vozes, 2008.

CALDART, Roseli Salete. Pedagogia do Movimento Sem Terra. 4.ed. São Paulo: Expressão Popular, 2012.

DELORY-MOMBERGER, Christine. Biografia e Educação: figuras do indivíduo projeto. Tradução de Maria da Conceição Passeggi. Natal, RN: EDUFRN, 2008.

FREIRE, Paulo. Pedagogia do Oprimido. 46.ed. Rio de Janeiro: Paz e terra, 2005.

FREIRE, Paulo. Educação como prática da liberdade. 44. ed. Rio de Janeiro: Paz e Terra. 2010. 
GIMONET, Jean-Claude. Praticar e Compreender a Pedagogia da Alternância dos CEFFAs. Tradução de Thierry de Burghgrave. Petrópolis - RJ: Editora Vozes, 2007.

HAGE, Salomão Antônio Mufarrej. Transgressão do Paradigma da (Multi)seriação como referência para a construção da Escola Pública do Campo. Educação \& Sociedade, Campinas, v. 35, n. 129, p.1165-1182, out./dez., 2014.

JOSSO, Marie-Christine. Experiências de vida e formação. 2.ed. São Paulo: Paulus, 2010.

MEDEIROS, Emerson Augusto de; AGUIAR, Ana Lúcia Oliveira. O Método (Auto) Biográfico e de Histórias de Vida: reflexões teórico-metodológicas a partir da pesquisa em educação. Revista Tempos e Espaços em Educação, v. 11, n. 27, p. 149-166, set. 2018. ISSN 2358-1425. Disponível em: https://seer.ufs.br/index.php/revtee/article/view/7884. Acesso em: 30 set. 2018. DOI: http://dx.doi.org/10.20952/revtee.v11i27.7884.

MEDEIROS, Emerson Augusto de; FERREIRA, Helena Perpétua de Aguiar; AGUIAR, Ana Lúcia Oliveira. Formação inicial de professores da educação do campo: a história do curso de pedagogia da terra da UERN. Revista Internacional de Formação de Professores, [S.1.], p. 325-341, jul. 2018. ISSN 2447-8288. Disponível em:

<https://periodicos.itp.ifsp.edu.br/index.php/RIFP/article/view/1270>. Acesso em: 30 Set. 2018.

MEDEIROS, Emerson Augusto de; VARELA, Sarah Bezerra Luna; NUNES, João Batista Carvalho. Abordagem Qualitativa: estudo na pós-graduação em educação da Universidade Estadual do Ceará (2004 - 2014). Holos, [S.1.], v. 2, p. 174-189, ago. 2017. ISSN 1807-1600. Disponível em: http://www2.ifrn.edu.br/ojs/index.php/HOLOS/article/view/4457. Acesso em: 30 set. 2018. Doi: https://doi.org/10.15628/holos.2017.4457.

MINAYO, Maria Cecília de Souza (Org.). Pesquisa Social: Teoria, Método e Criatividade. 26 ed. Petrópolis, RJ: Vozes, 2007.

MOLINA, Mônica Castagna. Educação do Campo e Pesquisa. Questões para reflexão. Brasil. Ministério do Desenvolvimento Agrário, 2006.

MOLINA, Mônica Castagna; ANTUNES-ROCHA, Maria Isabel. Educação do Campo, História, Práticas e Desafios no âmbito das Políticas de Formação de Educadores - Reflexões sobre o PRONERA e o PROCAMPO. Revista Reflexão e Ação, Santa Cruz do Sul, v.22, n.2, p. $220-253$, jun./dez. 2014.

NÓVOA, António. Prefácio. In: NÓVOA, António (Org.). Vida de Professores. 2.ed. Porto: Porto Editora, 1995, p. 7-9.

PINEAU, Gaston. A autoformação no decurso da vida: entre a hétero e a ecoformação. In: Nóvoa, António; Finger Mathias. O método (auto) biográfico e a formação. Natal, RN: EDUFRN; São Paulo: Paulus, 2010.

PINEAU, Gaston. As histórias de vida em formação: gênese de uma corrente de pesquisaação-formação existencial. Educação e Pesquisa, São Paulo, v.32, n.2, p. 329-343, maio/ago. 2006. 
SANTOS, Ramofly Bicalho dos; SILVA, Marizete Andrade da. Políticas Públicas em Educação do Campo: PRONERA, PROCAMPO e PRONACAMPO. Revista Eletrônica de Educação, v. 10, n. 2, p. 135-144, 2016.

SOUZA, Elizeu Clementino de. A arte de contar e trocar experiências: reflexões teóricometodológicas sobre história de vida em formação. Educação em Questão, Natal, v.25, n.11, p. 22-39, jan./abr. 2006.

TARDIF, Maurice. Saberes Docentes e Formação Profissional. 11 ed. Petrópolis, RJ: Vozes, 2010.

UNIVERSIDADE DO ESTADO DO RIO GRANDE DO NORTE. Projeto Pedagógico do Curso de Licenciatura em Pedagogia, do Projeto Pedagogia da Terra (Pedagogia da Terra). Mossoró, 2006 (Documento Digitalizado).

UNIVERSIDADE DO ESTADO DO RIO GRANDE DO NORTE. Relatório Final de Execução do Projeto Pedagógico do Curso de Licenciatura em Pedagogia, do Projeto Pedagogia da Terra (Pedagogia da Terra). Mossoró, 2011 (Documento Digitalizado).

\section{Como referenciar este artigo}

AGUIAR, A. L. O.; MEDEIROS, E. A. de. Formação Inicial de Professores da Educação do Campo: a experiência do PRONERA/UERN em narrativas (auto) biográficas. Revista on line de Política e Gestão Educacional, Araraquara, v. 22, n. 3, p. 1124-1139, set./dez., 2018. EISSN:1519-9029. DOI: 10.22633/rpge.v22i3.11789

Submetido em: $12 / 04 / 2018$

Aprovado em: 15/07/2018 